\title{
DIELECTRIC PROPERTIES OF NANOSTRUCTURED MIXED-OXIDE FILMS FORMED BY ANODIZING AI/Zr BILAYERS
}

\author{
Marcela SEPÚLVEDA, Kirill KAMNEV, Alexander MOZALEV \\ CEITEC - Central European Institute of Technology, Brno University of Technology, Brno, Czech Republic, EU \\ lina.sepulveda@ceitec.vutbr.cz, alexander.mozalev@ceitec.vutbr.cz
}

https://doi.org/10.37904/nanocon.2020.3693

\begin{abstract}
$\mathrm{ZrO}_{2}$ is a ceramic material suitable for high-temperature coatings, fuel cells as a solid proton-conducting electrolyte, and metal-oxide-semiconductor devices due to its recently explored promising dielectric properties. In this work, anodic nanostructured $\mathrm{ZrO}_{2}-\mathrm{Al}_{2} \mathrm{O}_{3}$ mixed films were synthesized on substrates via anodizing/reanodizing of a thin $\mathrm{Zr}$ layer through a porous anodic alumina (PAA) film at $40 / 240 \mathrm{~V}$ in $0.6 \mathrm{M}(\mathrm{COOH})_{2}$ and characterized by scanning electron microscopy and electrochemical impedance spectroscopy (EIS) including the measurements under various bias potentials. The films are composed of $\mathrm{ZrO}_{2}$ nanofingers penetrating the alumina pores, partially mixing with $\mathrm{Al}_{2} \mathrm{O}_{3}$. Nanofingers are anchored to a $\mathrm{ZrO}_{2}$ bottom-oxide nanofilm that forms under the PAA during anodization. The EIS reveals a nearly ideal dielectric behavior of the $\mathrm{ZrO}_{2}-\mathrm{Al}_{2} \mathrm{O}_{3}$ mixed-oxide nanostructured films. After dissolution of the PAA layer, the dielectric properties of the remaining zirconium oxide film become slightly worse, due to the specific structure and deviation from perfect stoichiometry. The $\mathrm{ZrO}_{2}-\mathrm{Al}_{2} \mathrm{O}_{3}$ mixed-oxide nanostructured film permittivity is calculated to be 11 , which is higher than that of alumina (9.8) due to the contribution of $\mathrm{ZrO}_{2}$ nanofingers grown in the alumina nanopores. After the PAA dissolution, the film permittivity increases substantially, up to 46 , which is twice the permittivity of $\mathrm{ZrO}_{2}$ (22) grown anodically on zirconium metal in a classical way. The $\mathrm{ZrO}_{2}-\mathrm{Al}_{2} \mathrm{O}_{3}$ mixed-oxide nanostructured films prepared via the PAA-assisted anodization are of high interest for potential application to various types of capacitors due to their near-ideal dielectric properties. The unique dielectric behavior of the PAA-dissolved $\mathrm{ZrO}_{2}$ film deserves detailed investigation in a future work.
\end{abstract}

Keywords: Anodizing, zirconium oxide, porous anodic alumina, dielectric

\section{INTRODUCTION}

Zirconium-oxide $\left(\mathrm{ZrO}_{2}\right)$ films have been extensively explored, mainly due to corrosion and hydrogen embrittlement resistance, which makes them suitable for selective $\mathrm{CO}$ sensors [1] and solid-electrolyte for fuel cells [2]. $\mathrm{ZrO}_{2}$ is also viewed as one of the promising high- $\mathrm{k}$ dielectric materials to replace $\mathrm{Ta}_{2} \mathrm{O}_{5}$. $\mathrm{Thin}_{\mathrm{ZrO}}$ films are also suitable dielectrics for volatile dynamic random access memory and for complementary metaloxide-semiconductor devices [3,4]. Commonly, thin $\mathrm{ZrO}_{2}$ films are synthesized using electron beam physical vapor deposition [5], chemical vapor deposition [6], atomic layer deposition [7], and chemical solution deposition [8]. Alternatively to the aforementioned techniques, the anodization method may be viewed as a simple and versatile approach for the synthesis of thin $\mathrm{ZrO}_{2}$ films since it does not require high-budget equipment, ultra-high vacuum conditions, or elevated temperatures [9]. Additionally, anodic $\mathrm{ZrO}_{2}$ films can be made nanostructured by so-called PAA-assisted anodization approach. When an Al layer is superimposed on a metal of interest, oxide nanostructures may form penetrating the initially grown porous anodic alumina (PAA) film during anodization [10]. In our previous works, we have reported that mixed aluminum-tantalum and aluminum-hafnium oxide films prepared by PAA-assisted anodization technique exhibit good dielectric performance, close to that of an ideal capacitor $[11,12]$. However, the electronic properties of mixed aluminumzirconium films prepared by anodization of $\mathrm{Al} / \mathrm{Zr}$ bilayers have never been studied. 
Here we report on the formation of nanostructured $\mathrm{ZrO}_{2}-\mathrm{Al}_{2} \mathrm{O}_{3}$ mixed films via PAA-assisted anodization of $\mathrm{Al} / \mathrm{Zr}$ bilayers sputter-deposited on Si wafers. The films were analyzed by scanning electron microscopy (SEM) and electrically characterized by electrochemical impedance spectroscopy (EIS), followed by the measurements under various bias potentials, before and after selectively dissolving the PAA overlayer. The results obtained provide insights into the electrical and electronic properties of the $\mathrm{ZrO}_{2}-\mathrm{Al}_{2} \mathrm{O}_{3}$ mixed films, assessing their applicability as dielectrics for electrolytic and thin-film capacitors.

\section{EXPERIMENTAL}

\subsection{Sample preparation}

One-side polished $\mathrm{Si}$ wafer covered with a $300 \mathrm{~nm}$ layer of $\mathrm{SiO}_{2}$ was used as a starting substrate. A layer of $\mathrm{Zr}, 200 \mathrm{~nm}$ thick, followed by a layer of $\mathrm{Al}, 1000 \mathrm{~nm}$ thick, were deposited on the substrate via magnetron sputtering of $\mathrm{Zr}$ and $\mathrm{Al}$ targets of respectively $99.95 \%$ and $99.999 \%$ purity. Anodizing of Al/Zr bilayer films was carried out in $0.6 \mathrm{M}(\mathrm{COOH})_{2}$ aqueous solution at room temperature in potentiodynamic mode by sweeping voltage from 0 to $40 \mathrm{~V}$ at a rate of $0.5 \mathrm{~V} \mathrm{~s}^{-1}$. Subsequently, re-anodizing was performed in the same electrolyte by sweeping the voltage from 40 to $240 \mathrm{~V}$ at a rate of $10 \mathrm{~V} \mathrm{~s}^{-1}$. Both processes were immediately followed by 3 min of current decay. After the anodizing and re-anodizing, the samples were thoroughly rinsed with deionized water and dried in an oven at $150{ }^{\circ} \mathrm{C}$ for $1 \mathrm{~h}$ in air at atmospheric pressure. For the $\mathrm{ZrO}_{2}-\mathrm{in}_{-}-\mathrm{Al}_{2} \mathrm{O}_{3}$ samples, a $30 \mathrm{~s}$ pore widening procedure was carried out to allow better permeation of buffer solution inside the pores (the 'PAA-in-built' samples). For selected samples, the PAA overlayer was fully dissolved in 1 wt $\%$ $\mathrm{NaOH}$ solution at room temperature (the 'PAA-free' samples).

\subsection{Sample characterization}

The surface morphology of the PAA-inbuilt and PAA-free samples was examined in a TESCAN MIRA II fieldemission scanning electron microscope. Cross-sections of experimental samples were observed in a FEI Verios 460L High-Resolution Scanning Electron Microscope.

\subsection{Electrochemical measurements}

EIS measurements were carried out in borate buffer $\left(0.5 \mathrm{M} \mathrm{H}_{3} \mathrm{BO}_{3} ; 0.05 \mathrm{M} \mathrm{Na} 7 \mathrm{~B}_{4} \mathrm{O}_{7}\right)$ aqueous solution, $\mathrm{pH}$ 7.5, using an Autolab PGSTAT204 Potentiostat/ Galvanostat with a FRA32M module (Metrohm). The electrochemical measurements were performed in a Teflon cell within an area of $0.27 \mathrm{~cm}^{2}$. After measuring the PAA-inbuilt samples, the PAA layer was etched away in the $\mathrm{NaOH}$ solution at $23^{\circ} \mathrm{C}$ without taking the sample out from the cell, then the sample was EIS measured again in the same cell. A two-electrode setup was employed for electrochemical measurements: a high-purity Au sheet was used as a counter electrode and positioned over the surface of the investigated sample; the Zr layer remaining after the anodization process underneath the oxide film was used the working electrode. EIS characterization was performed by applying a sinusoidal perturbation of $100 \mathrm{mV}$ in a frequency range from $1 \mathrm{MHz}$ to $0.01 \mathrm{~Hz}$. The bias was applied in a cathodic direction, from -0.5 to $-2.5 \mathrm{~V}$ with a step of $-0.5 \mathrm{~V}$. Experimental EIS data were analyzed by simulation and fitting software Autolab NOVA. All the EIS measurements were recorded from the open-circuit potential (OCP).

\section{RESULTS AND DISCUSSION}

\subsection{Structure of the anodized $\mathrm{Al} / \mathrm{Zr}$ bilayers}

Figure 1 shows the top, cross-sectional, and 3-D view SEM images of the oxide films obtained after the PAAassisted anodization of $\mathrm{Al} / \mathrm{Zr}$ bilayer films. It is seen that the film is complex comprises a self-ordered PAA layer (Figure 1a). Glimpsing inside the PAA layer with help of a cross-section SEM image (Figure $1 \mathbf{b}$ ), the 
PAA pores at the $\mathrm{Al}_{2} \mathrm{O}_{3} / \mathrm{ZrO}_{2}$ interface are filled with $\mathrm{ZrO}_{2}$ nanofingers. The top and 3-D SEM views after a complete PAA dissolution (Figures $1 \mathrm{c}, \mathbf{d}$ ) reveal an array of free-standing vertically aligned $\mathrm{ZrO}_{2}$ nanostructures. The location of these nanostructures corresponds to positions of pores in the PAA layer. The nanostructure bases are well distanced from each other, being anchored to a continuous $\mathrm{ZrO}_{2}$ bottom-layer film (darker areas on the top view). The structure of the films formed is outlined in the schematic image in Figure 2.
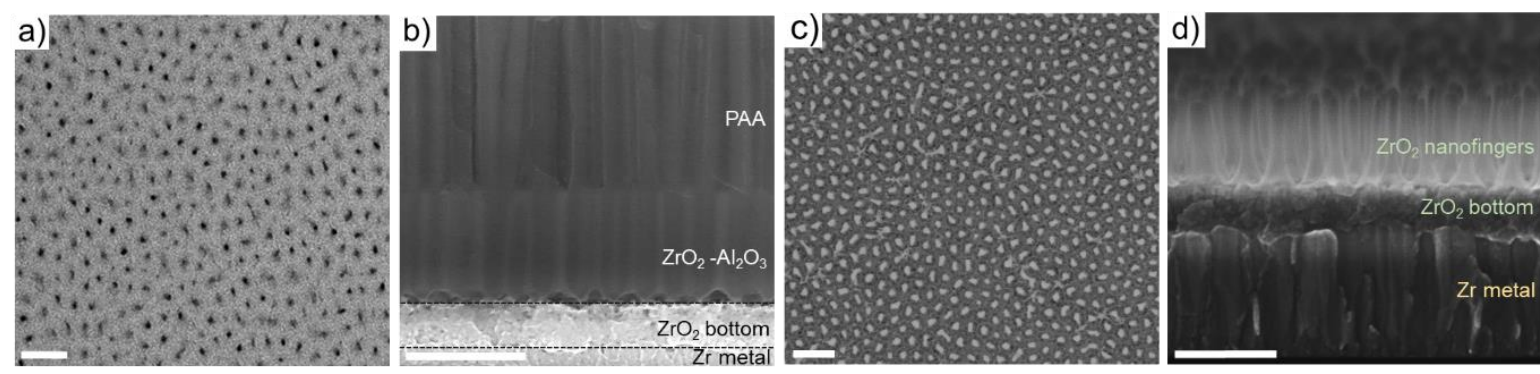

Figure 1 Top and cross-fractional SEM views of the (a, b) PAA-inbuilt and (c, d) PAA-free films, the scale bar in the SEM image corresponds to $300 \mathrm{~nm}$

a)

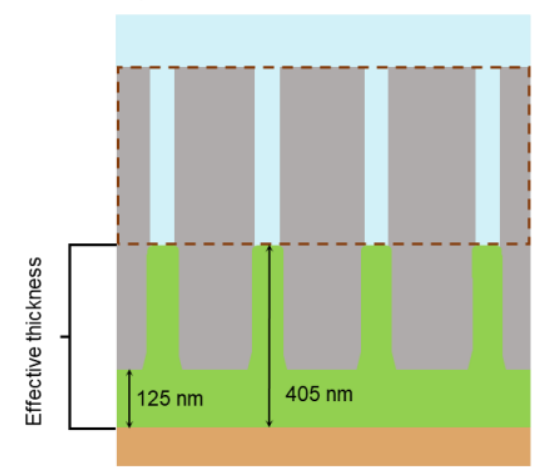

b)

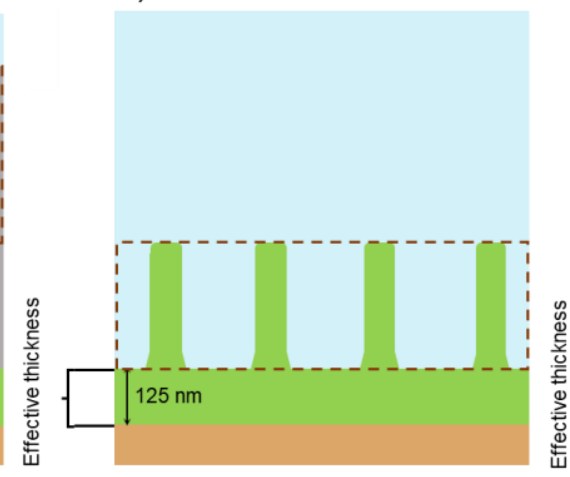

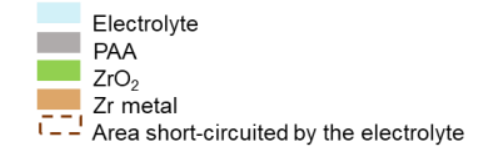

c)

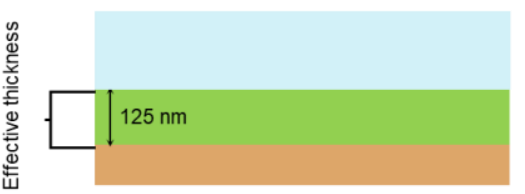

Figure 2 Schematic showing the development of the $\mathrm{ZrO}_{2}-\mathrm{Al}_{2} \mathrm{O}_{3}$ mixed films: a) the PAA-inbuilt film, b) the PAA-free film, and (c) a barrier-type anodic $\mathrm{ZrO}_{2}$ film

\subsection{Electrical measurements}

Electrical and electronic properties the PAA-inbuilt (Figures $1 \mathbf{a , b}$ ), and PAA-free (Figures $1 \mathbf{c}, \mathbf{d}$ ) films were characterized by EIS sweep at OCP (Figure 3). The bode diagrams suggest a simple equivalent circuit for the PAA-inbuilt and PAA-free films. In the circuit, $R_{s}$ is the solution resistance, $R_{1}$ is the film resistance, and $Q_{1}$ is the constant phase element (Figure 3 inset). Both the mixed $\mathrm{ZrO}_{2}-\mathrm{Al}_{2} \mathrm{O}_{3}$ nanostructured layer and the $\mathrm{ZrO}_{2}$ flat bottom-oxide layer are expected to contribute to the film impedance. During electrical measurements, the layer of PAA residing above the level of protruding $\mathrm{ZrO}_{2}$ nanofingers is short-circuited by the electrolyte (Figure 2 a) [12]. The phase shift of the PAA-inbuilt film is close to -90 degrees, which reflects a nearly ideal dielectric behavior of the film. However, after the complete dissolution of the PAA overlayer and thus excluding the $\mathrm{ZrO}_{2}$ nanofingers from the measurements, the film exhibits slightly different electrical behavior. The phase shift starts to deviate from -90 degrees, highlighting a slightly worse dielectric behavior. A worsened dielectric behavior can be explained by the differences in structure and crystallinity between the nanostructured and bottom-oxide $\mathrm{ZrO}_{2}$ layers. Due to the complex mechanism of oxide growth via the PAA-assisted anodizing, the bottom-oxide layer might possess more crystalline inclusions and less $\mathrm{ZrO}_{2-x}$ suboxides, which may alter its properties and worsen the dielectric behavior, or even introduce semiconducting properties to the oxide [12]. 


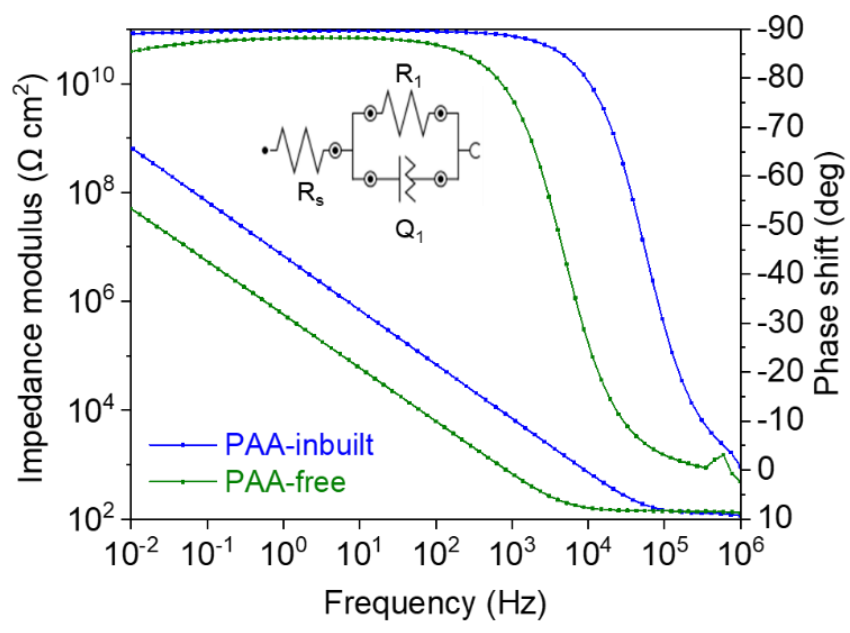

Figure 3 EIS characterization of the PAA-inbuilt $\mathrm{ZrO}_{2}-\mathrm{Al}_{2} \mathrm{O}_{3}$ films and PAA-free zirconium-oxide films: experimental (symbols) and fitted (solid lines) Bode plots at OCP

From the EIS measurements, the capacitance of the oxide films was calculated (Table 1). The capacitance of the $\mathrm{ZrO}_{2}-\mathrm{Al}_{2} \mathrm{O}_{3}$ mixed film is $24.0 \mathrm{nF} \mathrm{cm}{ }^{-2}$. However, PAA-free film shows a much higher capacitance of 326.8 $\mathrm{nF} \mathrm{cm}{ }^{-2}$. This is because the solution short circuits the free-standing $\mathrm{ZrO}_{2}$ nanostructures and only a bottom $\mathrm{ZrO}_{2}$ layer contributes to the measurement, thus drastically reducing the film thickness [12]. Due to the exclusion of the nanostructured $\mathrm{ZrO}_{2}$ upper layer from the measurement, one may expect that the capacitance and dielectric properties of the $\mathrm{ZrO}_{2}$ bottom oxide should be similar to those of anodically grown $\mathrm{ZrO}_{2}$ barriertype film of the same thickness. However, the capacitance for the barrier-type $\mathrm{ZrO}_{2}$ film is $152.4 \mathrm{nF} \mathrm{cm}{ }^{-2}$, which is roughly half the capacitance of the PAA-free $\mathrm{ZrO}_{2}$ nanofilm.

Table 1 Quantitative results of EIS of the PAA-inbuilt, PAA-free, and a barrier-type $\mathrm{ZrO}_{2}$ anodic films

\begin{tabular}{|l|l|l|l|}
\hline Film & Thickness $(\mathbf{n m})$ & Capacitance $\left(\mathbf{n F ~ c m} \mathbf{- 2}^{\mathbf{2}}\right.$ & Relative permittivity $\left(\boldsymbol{\varepsilon}_{\mathbf{r}}\right)$ \\
\hline PAA-Inbuilt & 405 & 24.0 & 11 \\
\hline PAA-free & 125 & 326.8 & 46 \\
\hline Barrier-type $\mathrm{ZrO}_{2}$ & 125 & 152.4 & 22 \\
\hline
\end{tabular}

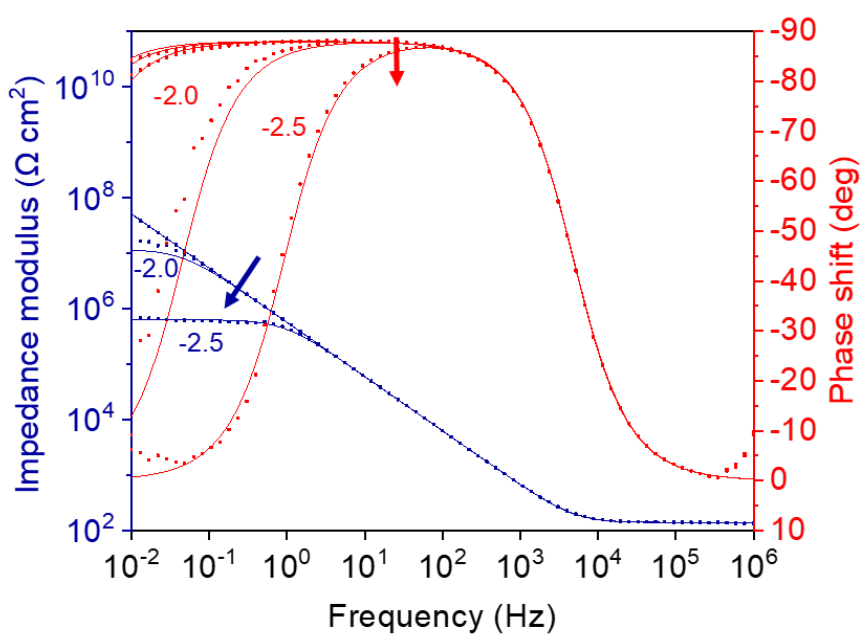

Figure 4 Bode plots of the PAA-free film under bias potentials ranging from -0.4 to $-2.5 \mathrm{~V}$ with -0.5 steps, experimental (symbols) and fitted (solid lines) 
To understand the abnormal behavior of the PAA-free $\mathrm{ZrO}_{2}$ film, EIS measurements under the bias potentials were carried out (Figure 4). This analysis reveals a potential-independent impedance behavior under a negative applied potential changing from -0.5 up to $-2.5 \mathrm{~V}$, confirming that the $\mathrm{ZrO}_{2}$ bottom oxide is a dielectric, not a semiconductor.

For each film type, dielectric constant (relative permittivity) was calculated from the capacitances and the thicknesses of the films measured by SEM (Table 1). The permittivity of the PAA-inbuilt sample $\varepsilon_{r}$ appears to be equal to 11, which is smaller than $\varepsilon_{r}$ of a pure $\mathrm{ZrO}_{2}$ known from the literature (22-24). As was seen in the SEM images, the PAA-inbuilt film consists of $\mathrm{ZrO}_{2}$ nanofingers intermittent by $\mathrm{Al}_{2} \mathrm{O}_{3}$ and anchored to a $\mathrm{ZrO}_{2}$ bottom oxide. The $\mathrm{ZrO}_{2}$ nanofingers surrounded by $\mathrm{Al}_{2} \mathrm{O}_{3}$ may be viewed as a set of parallel-connected capacitors while the $\mathrm{ZrO}_{2}$ bottom oxide lying underneath contributes as a capacitor connected in series. Thus, the biggest impact on the resultant capacitance is given by the parallel-connected $\mathrm{ZrO}_{2}$ nanofingers and the $\mathrm{Al}_{2} \mathrm{O}_{3}$ around them. As the volume of $\mathrm{Al}_{2} \mathrm{O}_{3}$ substantially exceeds that of the $\mathrm{ZrO}_{2}$ nanofingers in the mixedoxide film, it can be assumed that the capacitance of the $\mathrm{Al}_{2} \mathrm{O}_{3}$ portion dominates the resultant capacitance, making the resultant permittivity slightly higher than that of a pure $\mathrm{Al}_{2} \mathrm{O}_{3}$ (9.8) due to the $\mathrm{ZrO}_{2}$ nanofingers inclusions. After the PAA layer is completely dissolved, the permittivity rises drastically, up to 46 , neither corresponding to typical values reported for $\mathrm{ZrO}_{2}$ (22-24). One can assume that, after the PAA dissolution, the $\mathrm{ZrO}_{2}$ nanofingers would be short-circuited by the electrolyte and excluded from the measurement, leaving only the $\mathrm{ZrO}_{2}$ bottom-oxide film alone, which should have electric properties comparable with those of the $\mathrm{ZrO}_{2}$ film prepared by the convenient anodization of $\mathrm{Zr}$ metal. However, the normally prepared $\mathrm{ZrO}_{2}$ film of the same thickness exhibit more than twice as smaller capacitance and therefore, permittivity (22). It is clear that the $\mathrm{ZrO}_{2}$ bottom-oxide film derived from the PAA-assisted anodization exhibits unique electrical behavior in comparison with the $\mathrm{ZrO}_{2}$ films prepared by the convenient anodization of $\mathrm{Zr}$ metal. Since the bias assisted EIS analysis showed the purely dielectric behavior of the PAA-free $\mathrm{ZrO}_{2}$ film, the abnormal dielectric characteristics can be explained by unusual structural features of the oxide bottom layer. For example, having a high surface area, the nanofingers bases might not be completely excluded from the measurement and might influence film dielectric behavior after denudation of the $\mathrm{ZrO}_{2}$ nanostructures following PAA dissolution. It is of high interest to further investigate the unique dielectric properties of the alumina-zirconia mixed oxide films prepared by the PAA-assisted anodization of Al/Zr bilayers as they show an ideal dielectric behavior and can be potentially employed in various microelectronic devices, as well as to uncover the paradoxes behind the abnormal behavior of the $\mathrm{ZrO}_{2}$ bottom-oxide film in a future work.

\section{SUMMARY AND CONCLUSION}

Thin $\mathrm{Al} / \mathrm{Zr}$ layers anodically processed in $0.6 \mathrm{M}(\mathrm{COOH})_{2}$ at room temperature revealed the following two stages in their growth: (1) the formation of a PAA film at $40 \mathrm{~V}$ followed by the pore-assisted oxidation of the $\mathrm{Zr}$ underlayer at the same voltage and (2) the growth of $\mathrm{ZrO}_{2}$ nanostructures inside the PAA layer via re-anodizing to $240 \mathrm{~V}$. The $\mathrm{ZrO}_{2}-\mathrm{Al}_{2} \mathrm{O}_{3}$ mixed-oxide film consists of upward growing $\mathrm{ZrO}_{2}$ nanostructures protruding inside the pores and anchored to a $\mathrm{ZrO}_{2}$ bottom layer. The EIS characterization showed that the $\mathrm{ZrO}_{2}-\mathrm{Al}_{2} \mathrm{O}_{3}$ film behaves like an ideal dielectric. After the dissolution of the PAA overlayer, the film exhibits worsened dielectric behavior. The EIS examination under the bias confirms that the film is still dielectric. Surprisingly, the measured capacitance and calculated apparent permittivity of the PAA-free film are twice those of a barrier-type anodic $\mathrm{ZrO}_{2}$ film of the same thickness. The promising dielectric properties of the mixed $\mathrm{ZrO}_{2}-\mathrm{in}-\mathrm{Al}_{2} \mathrm{O}_{3}$ films will be explored more thoroughly in a future work in pursuit of better understanding and explaining the abnormal behavior of the $\mathrm{ZrO}_{2}$ bottom oxide.

\section{ACKNOWLEDGEMENTS}

The work was supported by a GACR grant no. 20-25486S. We acknowledge CzechNanoLab Research Infrastructure supported by MEYS CR (LM2018110). 


\section{REFERENCES}

[1] RAJABBEIGI, N., ElyASSI, B., KHODADADI, A. A., MOHAJERZADEH, S., MORTAZAVI, Y. and SAHIMI, M. Oxygen sensor with solid-state CeO2-ZrO2-TiO2 reference. Sensors and Actuators B: Chemical. 2005, vol.108, no. 1-2, pp. 341-345.

[2] MIURA, N., NAKATOU, M. and ZHUIYKOV, S. Impedancemetric gas sensor based on zirconia solid electrolyte and oxide sensing electrode for detecting total NOx at high temperature. Sensors and Actuators B: Chemical. 2003, vol. 93, no. 1-3, pp. 221-228.

[3] PANDA, D. and TSENG, T. Y. Growth, dielectric properties, and memory device applications of ZrO2 thin films. Thin Solid Films. 2013, vol. 531, pp. 1-20.

[4] FIORENTINI, V. and GULLERI, G. Theoretical evaluation of zirconia and hafnia as gate oxides for Si microelectronics. Physical review letters. 2002, vol. 89, no. 26, p. 266101.

[5] SCHULZ, U. and SCHMÜCKER, M. Microstructure of ZrO2 thermal barrier coatings applied by EB-PVD. Materials Science and Engineering: A. 2000, vol. 276, no. 1-3, pp.1-8.

[6] CHANG, J. P., LIN, Y. S. and CHU, K. Rapid thermal chemical vapor deposition of zirconium oxide for metaloxide-semiconductor field effect transistor application. Journal of Vacuum Science \& Technology B: Microelectronics and Nanometer Structures Processing, Measurement, and Phenomena. 2001, vol. 19, no. 5, pp.1782-1787.

[7] PERKINS, C. M., TRIPLETT, B. B., MCINTYRE, P. C., SARASWAT, K. C., HAUKKA, S. and TUOMINEN, M. Electrical and materials properties of $\mathrm{ZrO} 2$ gate dielectrics grown by atomic layer chemical vapor deposition. Applied Physics Letters. 2001, vol. 78, no. 16, pp. 2357-2359.

[8] HARDY, A., VAN ELSHOCHT, S., ADELMANN, C., CONARD, T., FRANQUET, A., DOUHÉRET, O. and HEYNS, M. Aqueous solution-gel preparation of ultrathin $\mathrm{ZrO}_{2}$ films for gate dielectric application. Thin Solid Films. 2008, vol. 516, no. 23, pp. 8343-8351.

[9] GRUBBS, C. A. Anodizing of aluminum. Metal Finishing. 1999, vol 97, no.1, pp.476-493.

[10] MOZALEV, A., SAKAIRI, M., SAEKI, I. and TAKAHASHI, H. Nucleation and growth of the nanostructured anodic oxides on tantalum and niobium under the porous alumina film. Electrochimica Acta. 2003, vol. 48, no.20-22, pp.3155-3170.

[11] MOZALEV, A., SAKAIRI, M. and TAKAHASHI, H. Structure, morphology, and dielectric properties of nanocomposite oxide films formed by anodizing of sputter-deposited Ta-Al bilayers. Journal of The Electrochemical Society. 2004, vol 151, no. 11, p. F257.

[12] BENDOVA, M., PYTLICEK, Z., PRASEK, J. and MOZALEV, A. The growth and unique electronic properties of the porous-alumina-assisted hafnium-oxide nanostructured films. Electrochimica Acta. 2019, vol. 327, p. 135029. 